\title{
Energy Analyses of Thermoelectric Renewable Energy Sources
}

\author{
Jarman T. Jarman ${ }^{1}$, Essam E. Khalil ${ }^{2}$, Elsayed Khalaf ${ }^{2}$ \\ ${ }^{1}$ Ministry of Interior, Riyadh, KSA \\ ${ }^{2}$ Faculty of Engineering, Cairo University, Giza, Egypt \\ Email: j_trad@hotmail.com
}

Received August 17, 2013; revised September 18, 2013; accepted September 25, 2013

Copyright (C) 2013 Jarman T. Jarman et al. This is an open access article distributed under the Creative Commons Attribution License, which permits unrestricted use, distribution, and reproduction in any medium, provided the original work is properly cited.

\begin{abstract}
The recent energy crisis and environmental burden are becoming increasingly urgent and drawing enormous attention to solar-energy utilization. Direct solar thermal power generation technologies, such as, thermoelectric, thermionic, magneto hydrodynamic, and alkali-metal thermoelectric methods, are among the most attractive ways to provide electric energy from solar heat. Direct solar thermal power generation has been an attractive electricity generation technology using a concentrator to gather solar radiation on a heat collector and then directly converting heat to electricity through a thermal electric conversion element. Compared with the traditional indirect solar thermal power technology utilizing a steam-turbine generator, the direct conversion technology can realize the thermal to electricity conversion without the conventional intermediate mechanical conversion process. The power system is, thus, easy to extend, stable to operate, reliable, and silent, making the method especially suitable for some small-scale distributed energy supply areas. Also, at some occasions that have high requirements on system stability, long service life, and noiselessness demand, such as military and deep-space exploration areas, direct solar thermal power generation has very attractive merit in practice. At present, the realistic conversion efficiency of direct solar thermal power technology is still not very high, mainly due to material restriction and inconvenient design. However, from the energy conversion aspect, there is no conventional intermediate mechanical conversion process in direct thermal power conversion, which therefore guarantees the enormous potential of thermal power efficiency when compared with traditional indirect solar thermal power technology [1].
\end{abstract}

Keywords: Solar Energy; Two Stage Concentrator; Mathematical Modeling; Thermal Analysis; Thermoelectric Power Generation

\section{Introduction}

Thermoelectric power generation is one of the current interests in clean energy research in view of direct solar power generation. Thermoelectric power generation becomes an attractive application. Recent research analyses were proposed in the open literature to cover the various aspects of energy generation [2-23]. Efforts have been devoted to investigate the thermoelectric power conversion theory and practical applications. These efforts have been under way from the following four aspects [24]:

1) Maximizing the temperature difference between two sides of thermoelectric devices by increasing the heat flow through thermoelectric devices with methods such as raising the solar concentration ratio.

2) Enhancing material thermoelectric characteristic. Seeking more suitable thermoelectric materials, such as nanometer materials, is the most useful and effec- tive way to improve thermoelectric conversion efficiency at present.

3) Implementing effective heat dissipation on the cold side, so that thermoelectric materials can work in the most suitable temperature range.

4) Carrying out design optimization and computer simulation to optimize the structure of thermoelectric elements and improve the packaging technology of devices.

This review is intended to present an account of the recent advances in developing the thermoelectric technologies specially, for direct solar thermal power generation. Both the fundamental issues and latest application research are illustrated and critical issues are discussed.

\section{Thermoelectric Applications}

Thermoelectric applications are broad. Thermoelectric 
materials had their first decisive long-term test with the start of intensive deep-space research. During the Apollo mission, thermoelectric materials were responsible for the power supply, and currently, radioisotope thermoelectric generators (RTEGs) are the power supplies (350 W) used in deep-space missions beyond Mars. Recently, the Cassini satellite was launched with three RETGs using $238 \mathrm{Pu}$ as the thermal energy source and $\mathrm{SiGe}$ as the thermoelectric conversion material. Smaller self-powered systems such as thermoelectric-powered radios were first mentioned in Russia around 1920; a thermoelectric climate-control system in a 1954 Chrysler automobile shows the scope of this technology. Currently, millions of thermoelectric climate-controlled seats that serve as both seat coolers and seat warmers are being installed in luxury cars. In addition, millions of thermoelectric coolers are used to provide cold beverages. Even wristwatches marketed by Seiko and Citizen and biothermoelectric pacemakers are being powered by the very small temperature differences within the body or between a body and its surroundings.

Thermoelectric materials were previously used primarily in niche applications, but with the advent of broader automotive applications and the effort to utilize waste-heat-recovery technologies; thermoelectric devices are becoming more prominent. The rising costs of fossil fuels have helped spawn a program between the Energy Efficiency and Renewable Energy office of the US Department of Energy and several automotive manufacturers to incorporate thermoelectric waste-heat-recovery technology in the design of heavy trucks. Indeed, without such systems, more than $60 \%$ of the primary energy of fossil fuels is lost worldwide as unusable waste energy; the loss is as high as $70 \%$ in some automobiles [25].

This field of thermoelectric also covers forthcoming applications and markets for remote "self-powered" systems for wireless data communications in the microwatt power range, as well as automotive systems and deepspace probes in the intermediate range of hundreds of watts. Researchers hope to produce systems of several kilowatts using waste heat energy from stand-alone woodstoves and also transform the huge amounts of waste energy from industrial furnaces and power plants.

Thermoelectric power generation is one of the current interests in clean energy research. Thermoelectric power generation technology has been widely used for many years power generation, heating and cooling applications. Although recent developments in nanotechnology have helped to improve the efficiency of the thermoelectric generators, they are not yet competitive with other electrical energy generation technologies from the efficiency perspective. Thermoelectric efficiency of these generators has generally been limited to about $5 \%-6 \%[2,21$, $24]$. However, they are easy to operate, compact, longer- lived, and require low maintenance cost. Also, the thermoelectric devices can utilize the waste heat to generate electricity; thus, the efficiency of the solar thermal power plant can be improved. Thermoelectric devices are friendly to the environment, so they have attracted increasing attention as a green and flexible source of electricity. Research in the area of thermoelectric power generation assists in identifying the best fields for implementation of this technology, and helps in reducing the time between the development of advanced materials and cost-effective thermoelectric power generation. The field of thermoelectricity began in 1822 with the discovery of the thermoelectric effect by Thomas Seebeck [3]. Seebeck found that, Figure 1(a), when the junctions of two dissimilar materials are held at different temperatures $(\Delta T)$, a voltage $(V)$ is generated that is proportional to $\Delta T$. The proportionality constant is the Seebeck coefficient or thermo power: $\alpha=-\Delta V / \Delta T$. When the circuit is closed, this couple allows for direct conversion of thermal energy (heat) to electrical energy. The conversion efficiency, $\eta_{\mathrm{TE}}$, is related to a quantity called the figure of merit, $Z T$ that is determined by three main material parameters: the thermo power $\alpha$, the electrical resistivity $\rho$, and the thermal conductivity $\kappa$. Heat is carried by both electrons $\left(k_{e}\right)$ and phonons $\left(\kappa_{\mathrm{ph}}\right)$, and $k=k_{e}+k_{p h}$. The quantity $Z T$ itself is defined as

$$
Z T=\frac{\alpha^{2} \sigma T}{k}=\frac{\alpha^{2} \sigma T}{\left(k_{e}+k_{p h}\right)}
$$

where $\sigma$ is the electrical conductivity.

A related effect was discovered a little bit later in 1834 by a French scientist Jean Peltier [4,5]. Peltier found, Figure 1(b), that when he applied a current in two pieces of coupled materials, a temperature gradient can be developed and the rate of heat absorbed or released at the junctions followed a relationship of $Q / d t=\Pi \cdot I$, where $\Pi$ is Peltier coefficient and I is the applied current. Two decades later, Lord Kelvin connected these two effects

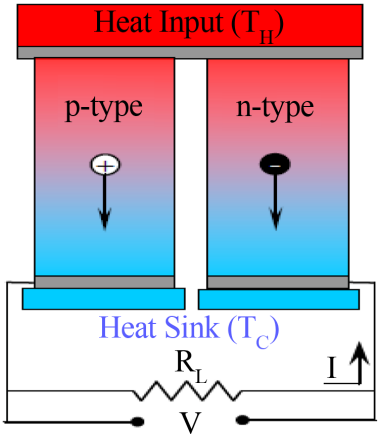

(a)

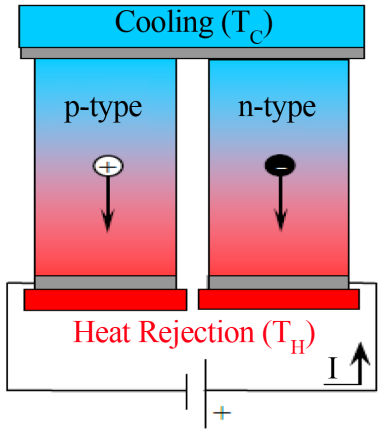

(b)
Figure 1. Arrangement of thermoelectric modules for (a) power generation by theSeebeck effect and (b) refrigeration by the Peltier effect. 
together by Kelvin relationship: $\Pi=\alpha T$, which was theoretically proved almost 80 years later by Lars Onsager in 1931. In the first 30 years of thermoelectric history, scientists discovered the basic effects and started to understand it macroscopically.

It was not until in 1911, that Altenkirch [3] derived thermoelectric efficiency and provided a microscopic understanding of thermoelectric phenomena. The knowledge of thermoelectricity was mainly developed in the 20 years after his derivation and led to the progress in the discovery of good bulk thermoelectric materials by 1970 . The efficiency of thermoelectricity $\left(\eta_{T E}\right)$ is determined by the dimensionless figure of merit (ZT):

$$
\eta_{T E}=\eta_{C}\left(\frac{\sqrt{1+Z T}-1}{\sqrt{1+Z T}+\frac{T_{C}}{T_{H}}}\right)
$$

where $\eta_{C}$ is the Carnot efficiency, $\eta_{C}=\left(T_{H}-T_{C}\right) / T_{H}$ and $T_{\mathrm{H}}$ and $T_{\mathrm{C}}$ are the hot and cold temperatures, respectively. Thus, a significant difference in temperature (large $\Delta T$ ) is also needed to generate sufficient electrical energy. Improvement of thermoelectric generator performance has been the objective of many of investigations. Kassas [6] carried out thermodynamic analysis of a thermoelectric device. He considered the thermoelectric diode and calculated the electronic as well as the Carnot efficiency of the device. He found that increasing emitter temperature increases the Carnot efficiency of the thermoelectric device. He also found that the second law efficiency increases with emitter to collector temperature ratio and reduces with increasing collector temperature as a result of the increase in collector current flow.

Yamashito [7] derived some thermal rate equations by considering the temperature dependencies of the electrical resistivity and thermal conductivity of the thermoelectric materials into the thermal rate equations. He derived the energy conversion efficiencies from both the new and conventional thermal rate equations and discussed the effect of the temperature dependency of the properties. He concluded that the temperature dependence of the electrical resistivity and thermal conductivity significantly influences the efficiency of the thermoelectric generator. Performance of thermoelectric devices was also studied by Yilbas and Sahin [8]. They formulated the optimum values of the slenderness ratio and external load parameter for maximizing the device efficiency. They found that for a fixed thermal conductivity ratio, the external load parameter increases with increasing the slenderness ratio while the electrical conductivity ratio of the $\mathrm{p}$ and $\mathrm{n}$ pins in the device reduces. Hsiao et al. [9] studied the development of thermoelectric generators for implementation in the internal combustion engine.
They found that installing the thermoelectric generators on the exhaust pipe would yield better results that installing them on the radiator. Champier et al. [10] studied the feasibility of using thermoelectric module in a biomass cook stove for generating electricity to power the fan and give light. They discussed the feasibility of adding commercial thermoelectric modules to the biomass cook stove to come up with the best position of the modules.

Design optimization for the thermoelectric generators has been subject of some previous investigations. Kubo et al. [11] carried out experimental and numerical investigation on the performance of thermoelectric device and studied the relationship between electrical power, conversion efficiency, and incision size and the cold side temperature. They found that the electrical power generated, the conversion efficiency, and the incision size depend on the cold side temperature. Guo et al. [12] studied the design performance of a low-temperature waste heat thermoelectric generator both analytically and experimentally. They found that expanding heat sink surface area in a proper range and enhancing cold-side heat transfer capacity can enhance the performance. Omer and Infield [26], investigated the geometrical optimization of the thermoelectric elements. The model considers the effect of the parameters that contribute to the heat transfer process associated with the thermoelectric devices in power generation mode. Their optimization of the element length was based on maximum power output from the device, rather than efficiency.

\section{Solar Thermoelectric Power Generation (STEG)}

The growing demand for energy throughout the world has caused great importance to be attached to the exploration of new sources of energy. Among the unconventional sources, solar energy is one of the most promising energy resources on earth and in space, because it is clean and inexhaustible. Applications of solar thermoelectric generator are attractive. The use of the solar thermoelectric generator usually combines a solar thermal collector with a thermoelectric generator, which delivers the electric energy. Tirtt et al. [13] reported that the infrared (IR) region of the solar spectrum can supply the needed hot temperature, $T_{\mathrm{H}}$. With regard to solar energy conversion, thermoelectric devices will likely utilize the IR spectrum of solar radiation as shown in Figure 2.

Telkes [15] gave a brief summary of the work in STEGs before 1954, and reported STEGs constructed of $\mathrm{ZnSb}$ and $\mathrm{Bi}-\mathrm{Sb}$ alloys. The maximum efficiency achieved of a flat-panel STEG was $0.63 \%$. Fewer than 50 times optical concentration, the efficiency reached $3.35 \%$. However, these efficiencies may be inaccurate; Telkes 


\begin{tabular}{|l|c|c|c|}
\cline { 2 - 4 } \multicolumn{1}{c|}{} & Wavelength & Spectrum & $\%$ \\
\hline Photovoltaic & $\sim 200-800 \mathrm{~nm}$ & UV \& visible light & 58 \\
\hline Thermoelectric & $\sim 800-3000 \mathrm{~nm}$ & IR & 42 \\
\hline
\end{tabular}

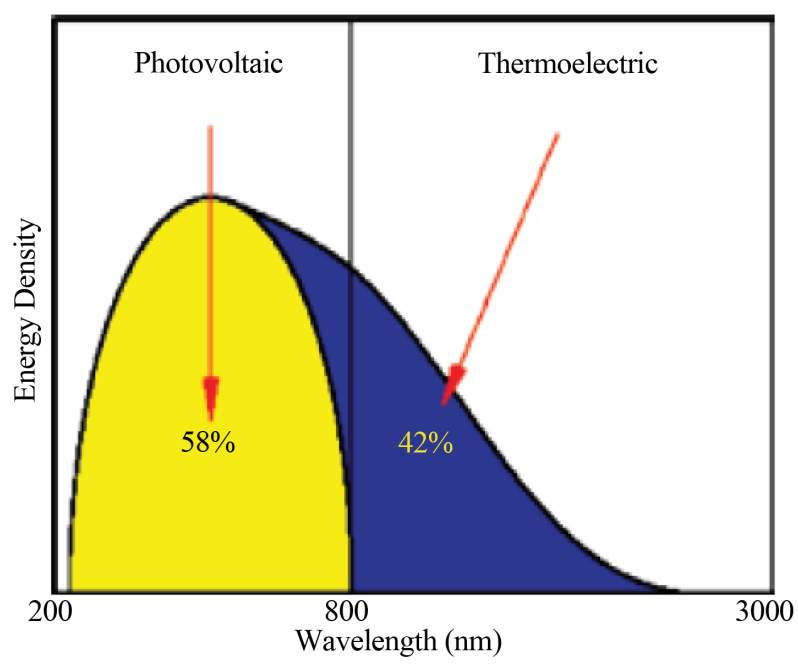

Figure 2. Sun radiates energy as a $6000 \mathrm{~K}$ blackbody radiator with part of the energyin the ultraviolet (UV) spectrum and part in the infrared (IR) spectrum [3].

used the average regional solar flux $\left(800 \mathrm{~W} / \mathrm{m}^{2}\right)$ to calculate efficiency, and not the actual incident flux. Telkes included air conduction and convection heat losses in analyzing the STEG cell performance. She treated radiation loss by an effective convection heat transfer coefficient. These analyses are valid only when the temperature rise on the absorber is small. Few papers have been published on STEGs since Telkes' report. Rush [16] investigated a flat-panel STEG configuration for space applications with an estimated maximum efficiency of $0.7 \%$. Goldsmid et al. [17] carried out experiments on STEGs using both flat-panel and optically concentrated configurations. For the flat-panel configuration, the reported generator efficiency is about $1.4 \%$ but the system efficiency is only about $0.6 \%$ due to radiation and conduction losses, comparable to that of Telke's report. Under 4 times optical concentration, their reported system efficiency decreased to $0.5 \%$ due to optical losses. Dent and Cobble [18] used a sun-tracking heliostat directing the solar radiation on a parabolic dish, which focused the sunlight onto thermoelectric generators using $\mathrm{PbTe}$ thermoelectric elements. A thermodynamic efficiency of $4 \%$ was estimated when the hot side was heated to $510^{\circ} \mathrm{C}$, based on the calculated heat input to the thermoelectric generators. Considering the optical concentration losses, the system efficiency of Dent and Cobble's generator at best would be similar to that of Telkes.

A thermodynamic analysis is presented by Amatya et al. [14] for predicting the thermal-to-electrical conver- sion efficiency for the generator. With solar concentration of 669 suns, a system efficiency of 3\% was measured for a commercial $\mathrm{Bi}_{2} \mathrm{Te}_{3}$ module with output power of $1.8 \mathrm{~W}$. Using novel thermoelectric materials such as n-type ErAs: (InGaAs) $)_{1-x}(\operatorname{InAlAs})_{\mathrm{x}}$ and p-type (AgS$\mathrm{bTe})_{\mathrm{x}}(\mathrm{PbSnTe})_{1-\mathrm{x}}$, a conversion efficiency of $5.6 \%$ can be achieved for a STG at 120× suns. Recently, Li et al. [19] proposed an experimental prototype concentration solar thermoelectric generator with improved total conversion efficiency. They developed a theoretical model of the concentration solar thermoelectric generator system to predict system performance based on the best available properties of different bulk thermoelectric materials found in the literature, including $\mathrm{Bi}_{2} \mathrm{Te}_{3}$, skutterudite, and silver antimony lead telluride alloys. They showed that the highest possible efficiency of the concentration solar thermoelectric generator can attain $9.8 \%, 13.5 \%$, and $14.1 \%$ for $\mathrm{Bi}_{2} \mathrm{Te}_{3}$, skutterudite, and silver antimony lead telluride alloys, respectively.

System-level theoretical analysis of solar thermoelectric generation is of great use and can give important theoretical support for developing practical applications. Chen [20] established a thermodynamic model to investigate the optimal performance of a STEG. In the model, four irreversibilities including finite-rate heat transfer between the thermoelectric devices and the external heat reservoirs, heat leak via the thermoelectric devices, Ohmic heat production inside the thermoelectric devices, and heat loss in the solar collector were taken into consideration. Some important theoretical results, such as the efficiency upper bound of solar TEGs, optimal operation temperature of solar collectors, maximum power output, and optimal load matching, were determined. The results are meaningful and could offer theoretical support for experimental investigation of solar-driven TEGs.

Chen [22] investigated the theoretical efficiency of solar thermoelectric generators (STEGs). A model was established including thermal concentration in addition to optical concentration. Based on the model, the maximum efficiency of STEGs is a product of the opto-thermal efficiency and the device efficiency. The device efficiency increases but the opto-thermal efficiency decreases with increasing hot side temperature, leading to an optimal hot-side temperature that maximizes the STEG efficiency. For a given optical concentration ratio, this optimal hot-side temperature depends on the thermoelectric materials' nondimensional figure-or-merit, the optical properties of wavelength-selective surface and the efficiency of the optical system. Operating in an evacuated environment, STEGs can have attractive efficiency with little or no optical concentration working in the low temperature range $\left(150^{\circ} \mathrm{C}-250^{\circ} \mathrm{C}\right)$ for which $\mathrm{Bi}_{2} \mathrm{Te}_{3}-$ based materials are suitable.

Solar thermoelectric generation is a significant option 
for space power supply. In the work of Lenoir et al., [23] the skutterudites thermoelectric materials were proposed for space solar TEG. Additionally, two space solar thermoelectric generator (STEG) concepts, namely, the flat plate configuration with identical collector and radiator areas which had a relatively small area and low mass and the STEG configuration with concentrators which had high concentration coefficient, were considered suitable for the space requirement. The theoretical comparison and discussion about the electrical performance as a function of sun-spacecraft distance of these two concepts were performed. The results showed that the output power higher than $400 \mathrm{~W}$ could be achieved when the distance was smaller than 0.45 AU. However, if the spacecraft moved to $0.30 \mathrm{AU}$, the collector temperature would increase up to $1000 \mathrm{~K}$, which might exceed the allowable temperature range of skutterudites thermoelectric materials. Therefore, the sun-spacecraft distance greatly affects power generation and reasonable protection is needed to maintain the temperature within the allowable range.

Omer et al. [25] presented a design procedure and thermal performance analysis of a two stage solar energy concentrator suited to combined heat and thermoelectric power generation. The concentrator is comprised of a primary one axis parabolic trough concentrator and a second stage compound parabolic concentrator mounted at the focus of the primary. The thermoelectric device is attached to the absorber plate at the focus of the secondary. A cooling tube is fitted to the cold side of the thermoelectric device to extract the waste heat and maintain a high temperature gradient across the device to improve conversion efficiency. The key requirements of the concentrator design are to be tolerant of tracking misalignment, maintain temperature gradients to suit thermoelectric generation and minimize heat losses. A design methodology is presented which allows interception of rays within an angular region $( \pm \delta)$. The results in a wider receiver for the parabolic trough concentrator would usually be used for a similar concentration ratio. The role of the second stage concentrator in limiting heat losses from the absorber plate is evaluated. Results indicate that in addition to improving the concentration efficiency, the second stage compound parabolic concentrator of the proposed design also inhibits convective air movement and, consequently, improves the overall performance of the solar concentrator.

Solar thermoelectric technology can also be used to improve the indoor environment and save building energy consumption. Maneewan et al. [27] performed a numerical and laboratory-scale investigation on attic heat gain reduction by means of thermoelectric roof solar collector (TERSC). Due to the incident solar radiation, the thermoelectric modules had a temperature difference between its hot and cold sides and generated direct current to drive a ventilating fan for cooling the TE-RSC and achieving better indoor ventilation so as to reduce ceiling heat gain. The analytical result showed that the decrease in the roof heat gain of $25 \%-35 \%$ and the corresponding induced air change rate of about $20-45 \mathrm{ACH}$ (air changes per hour) could be achieved. According to the economical analysis, the annual electrical energy saving was about $362 \mathrm{kWh}$ and the payback period was about 4.36 years. When compared to commercial insulations, although the ceiling heat transfer reduction in commercial insulations was relatively higher, the initial cost of TE-RSC was lower than microfiber or radiant barrier insulations by about $50 \%$ and $27 \%$, respectively. Therefore, the TE-RSC system is an attractive option by reason of its relatively low initial cost and simplicity.

A model of a two-stage semiconductor thermoelectricgenerator with external heat-transfer is built by Chen et al. [28]. Performance of the generator, assuming Newton's heat-transfer law applies, is analyzed using a combination of finite-time thermodynamics and non-equilibrium thermodynamics. The analytical equations about the power output versus the working electrical current, and the thermal efficiency versus working electrical-current are derived. For a fixed total heat-transfer surface-area for two heat-exchangers, the ratio of heat-transfer surface area of the high-temperature side heat-exchanger to the total heat-transfer surface-area of the heat-exchangers is optimized for maximizing the power output and the thermal efficiency of the thermoelectric-generator. For a fixed total number of thermoelectric elements, the ratio of number of thermoelectric elements of the top stage to the total number of thermoelectric elements is also optimized for maximizing both the power output and the thermal efficiency of the thermoelectric-generator. The effects of design factors on the performance are analyzed.

Active building envelope (ABE) systems are a new enclosure technology which integrate photovoltaic (PV) and thermoelectric (TE) technologies. In ABE systems, a PV system supplies electrical power to a TE heat-pump system, which can transfer heat in one direction or another depending on the direction of the current. Both the TE and PV systems are integrated by $\mathrm{Xu}$ et al. [29] into one enclosure surface. Hence, ABE systems have the ability to actively control the flow of heat across their surface when exposed to solar radiation. Applications for this technology include all types of enclosures that require cooling or heating, such as building enclosures. They developed various ABE system prototypes by using commercially available PV and TE technologies. In this study, two types of commercial available TE modules are studied for their potential application in an ABE prototype window system. They performed various experi- 
ments to determine the coefficient of performance for TE modules when operating under different voltage regimes, and have tested different electrical connection diagrams. Based upon the measured data, and results based on the computational models of a TE system, the most suitable type of TE modules, the voltage and current, and the preferable connection diagrams are discussed.

Smith [30] presented a model describing the performance of a thermoelectric system is developed and designed to operate over a large range of system configurations. The theoretical model is compared to the experimental results obtained from a Thermoelectric Power Generation System testing box tested under several configurations and conditions. Discrepancies between model and experiments are described with several model improvements developed and implemented. Finally, the model is incorporated with a heat transfer model and a pricing model to develop a preliminary optimization tool. The optimization tool is then used to analyze the viability of thermoelectric power generation in a hypothetical automotive application when compared with the operating costs of an alternator to develop viability curves based off the price of fuel.

Lertsatitthanakorn et al. [31] investigated the thermoelectric (TE) solar air collector, sometimes known as the hybrid solar collector, generates both thermal and electrical energies simultaneously. A double-pass TE solar air collector has been developed and tested. The TE solar collector was composed of transparent glass, air gap, an absorber plate, thermoelectric modules and rectangular fin heat sink. The incident solar radiation heats up the absorber plate so that a temperature difference is created between the thermoelectric modules that generate a direct current. Only a small part of the absorbed solar radiation is converted to electricity, while the rest increases the temperature of the absorber plate. The ambient air flows through the heat sink located in the lower channel to gain heat. The heated air then flows to the upper channel where it receives additional heating from the absorber plate. Improvements to the thermal and overall efficiencies of the system can be achieved by the use of the double-pass collector system and TE technology. Results showed that the thermal efficiency increases as the air flow rate increases. Meanwhile, the electrical power output and the conversion efficiency depend on the temperature difference between the hot and cold side of the TE modules. At a temperature difference of $22.8^{\circ} \mathrm{C}$, the unit achieved a power output of $2.13 \mathrm{~W}$ and the conversion efficiency of $6.17 \%$. Therefore, the proposed TE solar collector concept is anticipated to contribute to wider applications of the TE hybrid systems due to the increased overall efficiency.

Fan et al. [32] presented design details, theoretical analysis, and outcomes of a preliminary experimental investigation on a concentrator thermoelectric generator (CTEG) utilizing solar thermal energy. The designed CTEG system consisted of a parabolic dish collector with an aperture diameter of $1.8 \mathrm{~m}$ used to concentrate sunlight onto a copper receiver plate with $260 \mathrm{~mm}$ diameter. Four BiTe-based thermoelectric cells (TEC) installed on the receiver plate were used to convert the concentrated solar thermal energy directly into electric energy. A micro channel heat sink was used to remove waste heat from the TEC cold side, and a two-axis tracking system was used to track the sun continuously. Experimental tests were conducted on individual cells and on the overall CTEG system under different heating rates. Under maximum heat flux, a single TEC generator was able to produce $4.9 \mathrm{~W}$ for a temperature difference of $109^{\circ} \mathrm{C}$, corresponding to $2.9 \%$ electrical efficiency. The overall CTEG system was able to produce electric power of up to $5.9 \mathrm{~W}$ for a $35^{\circ} \mathrm{C}$ temperature difference with a hot-side temperature of $68^{\circ} \mathrm{C}$. The results of the investigation help to estimate the potential of the CTEG system and show concentrated thermoelectric generation to be one of the potential options for production of electric power from renewable energy sources.

Sark et al. [33] proposed to use the thermal waste by attaching thermoelectric (TE) converters to the back of PV modules, to form a PV-TE hybrid module. Due to the temperature difference over the TE converter additional electricity can be generated. Employing present day thermoelectric materials with typical figure of merits (Z) of $0.004 \mathrm{~K}^{-1}$ at $300 \mathrm{~K}$ may lead to efficiency enhancements of up to $23 \%$ for roof integrated PV-TE modules, as is calculated by means of an idealized model. The annual energy yield would increase by $14.7 \%-11 \%$, for two annual irradiance and temperature profiles studied, i.e., for Malaga, Spain, and Utrecht, the Netherlands, respectively. As new TE materials are being developed, efficiency enhancements of up to $50 \%$ and annual energy yield increases of up to $24.9 \%$ may be achievable. The developed idealized model, however, is judged to overestimate the results by about $10 \%$ for practical PV-TE hybrids. Sahin et al. [34] studied thermal efficiency of the topping cycle is analyzed and compared with its counterpart without the presence of the thermoelectric elements. Thermodynamic analysis for the efficiency of both the systems with and without thermoelectric generator was presented. The fluid flow and heat transfer in a tube with presence of thermoelectric elements resembling the solar heating system incorporated in the topping cycle are simulated numerically. It is found that, for a certain combination of operating and thermoelectric device parameters, thermal efficiency of the topping cycle becomes slightly higher than that of the same system without the presence of the thermoelectric generators.

A three-dimensional thermoelectric generator model is 
proposed and implemented (Chen et al. [35]) in a computational fluid dynamics (CFD) simulation environment (FLUENT). This model of the thermoelectric power source accounts for all temperature dependent characteristics of the materials, and includes nonlinear fluidthermal-electric multi-physics coupled effects. In solid regions, the heat conduction equation is solved with ohmic heating and thermoelectric source terms, and user defined scalars are used to determine the electric field produced by the Seebeck potential and electric current throughout the thermo elements. The current is solved in terms of the load value using user defined functions but not a prescribed parameter, and thus the field-circuit coupled effect is included. The model is validated by simulation data from other models and experimental data from real thermoelectric devices. Within the common CFD simulator FLUENT, the thermoelectric model can be connected to various CFD models of heat sources as a continuum domain to predict and optimize the system performance.

He et al. [36] presented an experimental and analytical study on incorporation of thermoelectric modules with glass evacuated-tube heat-pipe solar collectors. The integrated solar heat-pipe/thermoelectric module (SHP-TE) can be used for combined water heating and electricity generation. The experimental prototype unit comprises a glass evacuated-tube, a heat-pipe and a thermoelectric module with its one side attached to the condensation section of the heat-pipe and other side attached to a water channel. The heat-pipe transfers the solar heat absorbed within the glass evacuated-tube to the thermoelectric module. Under the condition of given solar irradiation and water temperature, the current, voltage and power outputs of the thermoelectric module are given for variable external electrical resistance. An analytical model of the prototype unit is presented to relate its thermal and electrical efficiencies with the solar irradiation, ambient temperature, water temperature, areas of the glass evacuated-tube and the thermoelectric module, and the length, cross-section area and number of thermo elements in the thermoelectric module. The analytic model is validated against the experimental data before it is used to optimize the design and operating parameters of the prototype for combined water heating and additional electricity generation.

Wotan et al. [37] reported on the design, fabrication and proof of concept of a multilayer fluidic packaging system enabling an increase in the output power performance of micro thermoelectric generators ( $\mu \mathrm{TEGs}$ ). The complete integration of the micro fluidic heat transfer system ( $\mu$ HTS) with a $\mu$ TEG is successfully demonstrated. The fabricated prototype is characterized with respect to its thermal and hydrodynamic performance as well as the generated output power. At a very low pumping power of $0.073 \mathrm{~mW} / \mathrm{cm}^{2}$, a heat transfer resistance of $0.74 \mathrm{~cm}^{2} \mathrm{~K} / \mathrm{W}$ is reached. The assembled device generated up to $1.47 \mathrm{~mW} / \mathrm{cm}^{2}$ at an applied temperature difference of $50 \mathrm{~K}$ and a fluid flow rate of $0.1 \mathrm{l} / \mathrm{min}$. Further system improvements and the potential of the proposed packaging approach are discussed.

It is well known that photovoltaic (PV) cells can only convert a portion of solar energy into electric power, and a large amount of remaining solar radiation mainly produces heat energy. Therefore, a lot of effort has been expended to combine the PV and thermoelectric technology in an efficient and powerful way. Most of these inventions are focused on the structure design [24]. Micallef [38] presented a Seebeck solar cell device, in which the materials used to form conductors in the $n$-type and $p$-type regions of the cells were chosen for their different thermoelectric characteristics. Therefore, electric power could be produced not only from the PV cells but also from the temperature gradient in the conductors resulting from solar radiation and waste heat generated in the PV cell. Multiple devices could be connected in series or parallel so as to enhance the output power. Hunt [39] presented a simple hierarchical structure, which had at least one thermoelectric module thermally attached to the PV module and could produce electricity both from the PV cell and thermoelectric module. This simple structure combines both PV and thermoelectric conversion.

Hecht [40] proposed another solar-energy conversion package which combined PV cell, thermoelectric conversion unit, and thermal heating system together. One of its embodiments unlike the system described previously, the thermoelectric cell and PV cell in this system were separated, and the irradiated surface of the PV cell was treated with selective spectrum reflective coating to allow high conversion PV wavelength energy to be absorbed by the PV cells, while the rest of less effective wavelength radiation would be reflected to the thermoelectric cell surface to produce electricity from heat; therefore higher efficiency could be achieved. Apart from that, making full use of solar radiation can also be achieved by performing a wavelength band division of solar light. The introduced solar radiation could be divided by wavelength band dividers. At first, the ultraviolet light would be separated by the wavelength band divider and reach the wavelength converter to be converted into visible light. Then the rest of solar radiation would pass through the wavelength band divider to be divided into visible light and infrared light. After these wavelengths band division processes, the visible light would reach the photoelectric converter where it could be converted into electric energy, and the infrared light would be converted by a thermoelectric converter into electric energy through thermal energy. Therefore, more efficient 
solar-energy utilization can be achieved using this compound system.

\section{Thermoelectric Materials}

Thermoelectric material which greatly affects the efficiency is of huge importance for solar thermoelectric power generation. Apart from the large Seebeck coefficient, good electrical conductivity, and small thermal conductivity, the thermoelectric materials must present excellent thermal and chemical stability at high temperature when used under the concentrated solar radiation. A great deal of research on thermoelectric material has been conducted over the past 50 years, and the literature is rich. The three factors $\alpha, \sigma$ and $k$ are interrelated and make it quite challenging to optimize $Z T$. Equation (1.2) emphasizes that high Seebeck coefficients are important for a good thermoelectric material. Nevertheless, an increase in $\alpha$ is almost always accompanied with a decrease in $\sigma$. Typically semiconductors and semimetals have higher $\alpha$ but lower $\sigma$ than metals because of their rather lower carrier concentrations At room temperature, $T=300 \mathrm{~K}$, desired values for the thermoelectric parameters are $\alpha=225 \mu \mathrm{V} / \mathrm{K}, \sigma=10^{5} \Omega^{-1} \cdot \mathrm{m}^{-1}$, and $k=1.5$ $\mathrm{W} / \mathrm{m} \cdot \mathrm{K}$, which results in a $Z T \approx 1$. These values are typical for the best $T E$ materials such as $\mathrm{Bi}_{2} \mathrm{Te}_{3}$ and $\mathrm{Sb}_{2} \mathrm{Te}_{3}$ alloys, which are presently used by industry in devices that operate near room temperature and are well investigated. Current $T E$ devices operate at an efficiency of about $5 \%-6 \%$. By increasing $Z T$ by a factor of 4 predicted efficiencies can increase to $30 \%$ [5].

In order to achieve a sufficient conversion efficiency $\eta$ at the given temperature, values of at least $Z T \sim 1$ are required. The maximum conversion efficiency is thermodynamically limited by the Carnot efficiency. As was shown by (Yang and Caillat [41]), a figure of Merit in the range of $2<Z T<3$ results in conversion efficiencies of $\sim 50 \%$ of the Carnot efficiency. The real conversion efficiency depends not solely on the materials properties, but also on the construction and geometry of the TE device, as well as on the macroscopic heat and electronic transport. Commercial thermoelectric devices are based on $\mathrm{Bi}_{2} \mathrm{Te}_{3}$ because this material exhibits a relatively high figure of Merit [41]. Disadvantages of $\mathrm{Bi}_{2} \mathrm{Te}_{3}$ compounds are their limited chemical stability at high temperatures in air and their toxicity. Therefore, complex metal oxide ceramics as alternative materials are promising candidates for high temperature applications as they are inert at high temperatures in air, non-toxic, and low cost materials [41]. Among these oxides, $\mathrm{Na}_{\mathrm{x}} \mathrm{Co}_{2} \mathrm{O}_{4}$ is especially interesting as it shows a high figure of Merit, $Z T \sim 0.8$ at $T=800 \mathrm{~K}$. The production of single crystals with defined and stable stoichiometry is difficult, though. In contrast, perovskite-type materials based on manganate and cuprate can be easily synthesized with controllable compo- sition and TE properties.

Current thermoelectric materials, as shown in Figure 3 [13], have $Z T=1$, and new materials with $Z T$ values of 2 - 3 are sought to provide the desired conversion efficiencies. The current materials exhibit conversion efficiencies of $7 \%-8 \%$ depending on the specific materials and the temperature differences involved. With regard to solar energy conversion, thermoelectric devices will likely utilize the IR spectrum of solar radiation. For example, a thermoelectric power conversion device with $Z T=3$ operating between $500^{\circ} \mathrm{C}$ and $30^{\circ} \mathrm{C}$ (room temperature) would yield about $50 \%$ of the Carnot efficiency.

Tirtt et al. [42] proved that a value of $Z T>4$ does not significantly increase the conversion efficiency over that of a material with $Z T=2-3.5$ Therefore, they believed that the "Holy Grail" of thermoelectric materials research is to find bulk materials (both $n$-type and $p$-type) with a $Z T$ value on the order of $2-3$ (efficiency $=15 \%-20 \%$ ) with low parasitic losses (e.g., contact resistance, radiation effects, and interdiffusion of the metals) and low manufacturing costs. With respect to solar energy, these materials would need to operate at about $1000 \mathrm{~K}$ $\left(\approx 700^{\circ} \mathrm{C}\right)$. The solar energy conversion process could be envisioned where a high-efficiency solar collector turns the sunlight (from the IR spectrum) into heat that is then transformed by the thermoelectric devices into usable electricity. In addition, the solar energy could be stored in a thermal bath and transformed into electricity through thermoelectrics when the sun was not shining.

Sano et al. [43] presented an attempt to improve the performance of a thermoelectric element/module for power generation by taking the following two approaches:

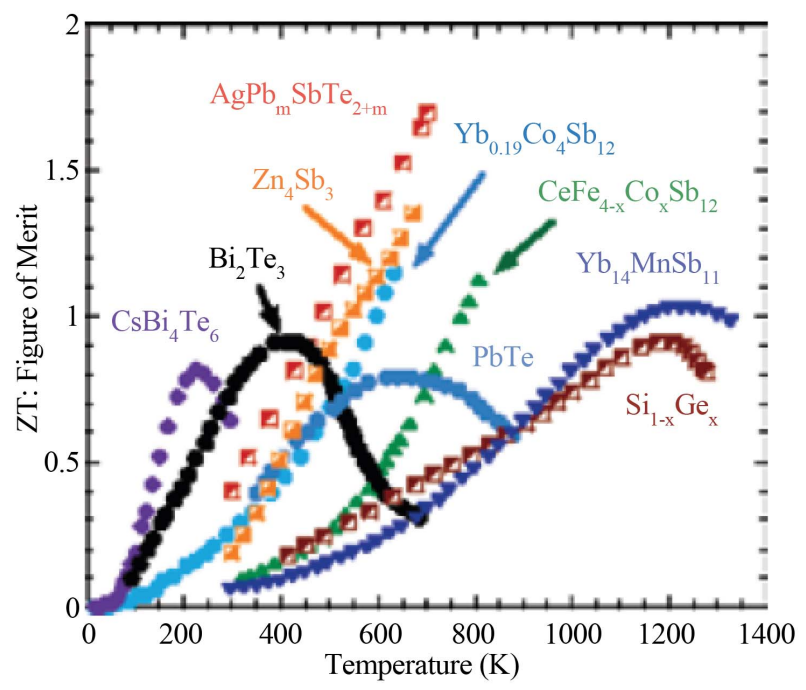

Figure 3. Figure of merit $(\mathrm{ZT})$ as a function of temperature forseveral high-efficiency bulk thermoelectric materials [29]. 
- Improving the basic characteristic $(Z)$ of thermoelectric element (Improve the characteristics of the element at room temperature and thereby improve them at higher temperatures).

- Shifting the peak of $Z$ toward the high temperature side (Even if the value of $Z$ in the low temperature region decreases, the overall efficiency of the element improves as the value of $Z$ in the high temperature region increases).

With the aim of improving the figure of merit, $Z$, of a thermoelectric element, they applied plasma treatment to the raw material powder as described in [43]. Concerning the shift of the peak of $Z$ toward the high temperature side, their experimental results introduced that the n-type maintains an improved characteristic in the high-temperature region without causing the low-temperature characteristic to decrease significantly. The figure of merit of the $p$ type at low temperatures decreased markedly. However, the average performance index in the entire working temperature range improved.

\section{The Future of Thermoelectric Materials}

The future expansion of thermoelectric energy conversion technologies is tied primarily to enhanced materials performance along with better thermal management design. The best thermoelectric material should behave as a so-called phonon-glass-electron-crystal; that is, it should minimally scatter electrons, as in a crystalline material, whereas it should highly scatter phonons, as in an amorphous material. Materials researchers are now investigating several systems of materials including typical narrow-band gap semiconductors (half-Heusler alloys), oxides, and cage-structure materials (skutterudites and clathrates). More exotic structures that exhibit reduced dimensionality and nanostructures have been the focus of much recent research, including super lattices, quantum dots, and nanodot bulk materials. Also, recent progress in nanocomposites, mixtures of nano materials in a bulk matrix, has generated much interest and hope for these materials. The emerging field of these thermoelectric nanocomposites appears to be one of the most promising recent research directions. Such nanocomposites could allow for higher $Z T$ values by reducing thermal conductivity while maintaining favorable electronic properties. With new higher efficiency materials, the field of harvesting waste energy through thermoelectric devices will become more prevalent [44-47].

The most stable, long-term, and readily available worldwide energy source is that of solar energy. The issue has always been low-cost transformation and storage. Other alternative energy technologies such as fuel cells, wind energy, and thermoelectric will provide some assistance in meeting our future energy needs. Many hybrid systems will be needed, and thermoelectric is able to work in tandem with many of these other technologies, especially solar as it can use the heat source provided by solar radiation. Over the past decade, thermoelectric materials have been developed with $Z T$ values that are a factor of 2 larger than those of previous materials. Another $50 \%$ increase in $Z T$ (to $Z T \approx 3$ ) with the appropriate material characteristics and costs will position thermoelectric to be a significant contributor to our energy needs, especially in waste heat or solar energy conversion. The likelihood of achieving these goals appears to be within reach in the next several years. Furthermore, some contribution from many of these alternative energy technologies such as thermoelectric will be needed in order to fulfill the world's future energy needs.

\section{Concluding Remarks}

It can be seen that although much effort has been made to develop direct solar thermal power generation technologies, the conversion potential and practical applications are still not widely used. In order to make full use of its advantages and develop practical civil devices, more effort should be devoted to material research, structure optimization, and practical application development.

\section{REFERENCES}

[1] S. B. Riffat and X. L. Ma, "Thermoelectrics: A Review of resent and Potential Applications," Applied Thermal Engineering, Vol. 23, No. 8, 2003, pp. 913-935.

http://dx.doi.org/10.1016/S1359-4311(03)00012-7

[2] K. Soteris, "Solar Energy Engineering: Processes and Systems," Elsevier Inc., Berlin, 2009.

[3] X. F. Qiu, "Nano-Structured Materials for Energy Conversion Case," Ph.D. Thesis, Western Reverse University, Cleveland, 2008.

[4] D. E. Demirocak, "Thermodynamic and Economic Analysis of a Solar Thermal Powered Adsorption Cooling System," MSc. Thesis in Mechanical Engineering Department, Middle East Technical University, Ankara, 2008.

[5] R. H. Hyde, "Growth and Characterization of Thermoelectric Ba8Ga16Ge30 Type-I Clathrate Thin-Films Deposited by Pulsed Dual-Laser Ablation," Ph.D. Thesis, College of Arts and Sciences, University of South Florida, Tampa, 2011.

[6] M. Kassas, "Thermodynamic Analysis of a Thermoelectric Device," International Journal of Exergy, Vol. 4, No. 2, 2007, pp. 168-179. http://dx.doi.org/10.1504/IJEX.2007.012064

[7] O. Yamashita, "Effect of Linear Temperature Dependence of Thermoelectric Properties on Energy Conversion Efficiency," Energy Conversion and Management, Vol. 49, No. 11, 2008, pp. 3163-3169. http://dx.doi.org/10.1016/j.enconman.2008.05.019

[8] B. S. Yilbas and A. Z. Sahin, "Thermoelectric Device and 
Optimum External Load Parameter and Slenderness Ratio," Energy, Vol. 35, No. 12, 2010, pp. 5380-5384. http://dx.doi.org/10.1016/i.energy.2010.07.019

[9] Y. Y. Hsiao, W. C. Chang and S. L. Chen, "A Mathematic Model of Thermoelectric Module with Applications on Waste Heat Recovery from Automobile Engine," Energy, Vol. 35, No. 3, 2010, pp. 1447-1454. http://dx.doi.org/10.1016/j.energy.2009.11.030

[10] D. Champier, J. P. Bedecarrats, M. Rivaletto and F. Strub, "Thermoelectric Power Generation from Biomass Cook Stoves," Energy, Vol. 35, No. 2, 2010, pp. 935-942. http://dx.doi.org/10.1016/j.energy.2009.07.015

[11] M. Kubo, M. Shinoda, T. Furuhata and K. Kitagawa, "Optimization of the Incision Size and Cold-End Temperature of a Thermoelectric Device," Energy, Vol. 30, No. 11-12, 2005, pp. 2156-2170.

[12] X. Gou, H. Xiao and S. Yang, "Modeling, Experimental Study and Optimization on Low-Temperature Waste Heat Thermoelectric Generator System," Applied Energy, Vol. 87, No. 10, 2010, pp. 3131-3136. http://dx.doi.org/10.1016/i.apenergy.2010.02.013

[13] T. M. Tritt, H. Böttner and L. Chen, "Thermoelectrics: Direct Solar Thermal Energy Conversion," MRS Bulletin, Vol. 33, No. 4, 2008, pp. 366-368.

[14] R. Amatya and R. J. Ram, "Solar Thermoelectric Generator for Micro powerapplications," Journal of Electronic Materials, Vol. 39, No. 9, 2010, pp. 1735-1740. http://dx.doi.org/10.1007/s11664-010-1190-8

[15] M. Telkes, "Solar Thermoelectric Energy Generators," Journal of Applied Physics, Vol. 23, No. 6, 1954, pp. 765-777. http://dx.doi.org/10.1063/1.1721728

[16] R. Rush, "Solar Flat Plate Thermoelectric Generator Research,” Tech. Doc. Rep. Air Force, AD 605931, 1964.

[17] H. J. Goldsmid, J. E. Giutronich, and M. M. Kaila, "Solar Thermoelectric Generation Using Bismuth Telluride Alloys," Solar Energy, Vol. 24, 5, 1980, pp. 435-440. http://dx.doi.org/10.1016/0038-092X(80)90311-4

[18] C. L. Dent and M. H. Cobble, Proceedings of the 4th International Conference on Thermoelectric Energy Conversion, New York, 1982, pp. 75-78.

[19] P. Li, L. Cai, P. Zhai, X. Tang, Q. Zhang and M. Niino, "Design of Concentration Solar Thermoelectric Generator," Journal of Electronic Materials, Vol. 39, No. 9, 2010, pp. 1522-1530. http://dx.doi.org/10.1007/s11664-010-1279-0

[20] J. Chen, "Thermodynamic Analysis of a Solar-Driven Thermoelectric Generator," Journal of Applied Physics, Vol. 79, No. 5, 1996, pp. 2717-2721. http://dx.doi.org/10.1063/1.361143

[21] D. M. Rowe, "Thermoelectrics, an EnvironmentallyFriendly Source of Electrical Power," Renewable Energy, Vol. 16, No. 1-4, 1999, pp. 1251-1256. http://dx.doi.org/10.1016/S0960-1481(98)00512-6

[22] G. Chen, "Theoretical Efficiency of Solar Thermoelectric Energy Generators," Journal of Applied Physics, Vol. 109, No. 10, 2011, pp. 104908-104908-8. http://dx.doi.org/10.1063/1.3583182

[23] B. Lenoir, A. Dauscher, P. Poinas, H. Scherrer, and L.
Vikhor, "Electrical Performance of Skutterudites Solar Thermoelectric Generators," Applied Thermal Engineering, 23, No. 11, 2003, pp. 1407-1415. http://dx.doi.org/10.1016/S1359-4311(03)00065-6

[24] Y. Deng and J. Liu, "Recent Advances in Direct Solar Thermal Power Generation," Journal of Renewable and Sustainable Energy, Vol. 1, No. 5, 2009, Article ID: 052701. http://dx.doi.org/10.1063/1.3212675

[25] S. A. Omer and D. G. Infield, "Design and Thermal Analysis of a Two Stage Solar Concentrator for Combined Heat and Thermoelectric Power Generation," Energy Conversion \& Management, Vol. 41, No. 7, 2000, pp. 737-756. http://dx.doi.org/10.1016/S0196-8904(99)00134-X

[26] S. A. Omer and D. G. Infield, "Design Optimization of Thermoelectric Devices for Solar Power Generation," Solar Energy Materials and Solar Cells, Vol. 53, No. 1-2, 1998, pp. 67-82. http://dx.doi.org/10.1016/S0927-0248(98)00008-7

[27] S. Maneewan, J. Hirunlabh, J. Khedari, B. Zeghmati and S. Teekasap, "Heat Gain Reduction by Means of Thermoelectric Roof Solar Collector," Solar Energy, Vol. 78, No. 4, 2005, pp. 495-503. http://dx.doi.org/10.1016/j.solener.2004.08.003

[28] L. Chen, J. Li, F. Sun and C. Wu, "Performance Optimization of a Two-Stage Semiconductor Thermoelectric-Generator," Applied Energy, Vol. 82, No. 4, 2005, pp. 300-312.

http://dx.doi.org/10.1016/j.apenergy.2004.12.003

[29] X. Xu, S.V. Dessel and A. Messacb, "Study of the Performance of Thermoelectric Modules for Use in Active Building Envelopes," Building and Environment, Vol. 42, No. 3, 2007, pp. 1489-1502. http://dx.doi.org/10.1016/j.buildenv.2005.12.021

[30] K. D. Smith, "An Investigation into the Viability of Heat Sources for Thermoelectric Power Generation Systems," MSc. Thesis, Department of Mechanical Engineering, Rochester Institute of Technology, Rochester, 2009.

[31] C. Lertsatitthanakorn, N. Khasee, S. Atthajariyakul, S. Soponronnarit, A. Therdyothin and R. O. Suzuki, "Performance Analysis of a Double-Pass Thermoelectric Solar Air Collector," Solar Energy Materials \& Solar Cells, Vol. 92, No. 9, 2008, pp. 1105-1109. http://dx.doi.org/10.1016/j.solmat.2008.03.018

[32] H. Fan, R. Singh and A. Akbarzadeh, "Electric Power Generation from Thermoelectric Cells Using a Solar Dish Concentrator," Journal of Electronic Materials, Vol. 40, No. 5, 2011, pp. 1311-1320. http://dx.doi.org/10.1007/s11664-011-1625-x

[33] W. G. J. H. M. Van Sark, "Feasibility of PhotovoltaicThermoelectric Hybrid Modules," Applied Energy, Vol. 88 , No. 8, 2011, pp. 2785-2790. http://dx.doi.org/10.1016/j.apenergy.2011.02.008

[34] A. Z. Sahin, B. S. Yilbas, S. Z. Shuja and O. Momin, "Investigation into Topping Cycle: Thermal Efficiency with and without Presenceof Thermoelectric Generator," Energy, Vol. 36, No. 7, 2011, pp. 4048-4054. http://dx.doi.org/10.1016/j.energy.2011.04.044

[35] M. Chen, L. A. Rosendahl and T. Condra, "A Three- 
Dimensional Numerical Model of Thermoelectric Generators in FluidPower Systems," International Journal of Heat and Mass Transfer, Vol. 54, No. 1-3, 2011, pp. 345355.

http://dx.doi.org/10.1016/j.ijheatmasstransfer.2010.08.02 $\underline{4}$

[36] W. He, Y. Su, Y. Q. Wang, S. B. Riffat and J. Ji, “A Study on Incorporation of Thermoelectric Modules with Evacuated-Tubeheat-Pipe Solar Collectors," Renewable Energy, Vol. 37, No. 1, 2012, pp. 142-149.

[37] N. Wojtas, E. Schwytera, W. Glatzb, S. Kühnea, W. Escherc and C. Hierolda, "Power Enhancement of Micro Thermoelectric Generators by Micro Fluidic Heat Transfer Packaging," Sensors and Actuators A: Physical, Vol. 188, 2012, pp. 389-395.

[38] J. A. Micallef, US Patent No. US2008053514-A1, 2008.

[39] R. D. Hunt, Patent No. WO2004004016-A1, 2004.

[40] D. H. Hecht, US Patent No. US2007289622-A1, 2007.

[41] P. Tomeš, M. Trottmann, C. Suter, M. Aguirre, A. Steinfeld, P. Haueter and A. Weidenkaff, "Thermoelectric Oxide Modules (TOMs) for the Direct Conversion of Simulated Solar Radiation into Electrical Energy," Materials, Vol. 3, No. 4, 2010, pp. 2801-2814. http://dx.doi.org/10.3390/ma3042801

[42] T. M. Tritt and M. A. Subramanian, "Thermoelectric Materials, Phenomena, and Applications: A Bird's Eye View,"
MRS Bulletin, Vol. 31, No. 3, 2006, pp. 188-198. http://dx.doi.org/10.1557/mrs2006.44

[43] S. Sano, H. Mizukami and H. Kaibe, "Development of High-Efficiency Thermoelectric Power Generation System," Komatsu Technical Report, Vol. 49, No. 152, 2003, pp. 1-7.

[44] Q. Yao, L. Chen, W. Zhang, S. Liufu and X. Chen, "Enhanced Thermoelectric Performance of Single-Walled Carbon Nanotubes/Polyaniline Hybrid Nanocomposites," ACS Nano, Vol. 4, No. 4, 2010, pp. 2445-2451. http://dx.doi.org/10.1021/nn1002562

[45] P. Ahadi, N. Haeri and A. Nazari, "The Use of Nanotechnology In Solar Systems," Australian Journal of Basic and Applied Sciences, Vol. 5, No. 11, 2011, pp. 14501456.

[46] R. Venkatasubramanian, C. Watkins, D. Stokes, J. Posthill and C. Caylor, "Energy Harvesting for Electronics with Thermoelectric Devices Using Nanoscale Materials," IEEE International on Electron Devices Meeting, Washington DC, 10-12 December 2007, pp. 367-370.

[47] A. I. Hochbaum and P. Yang, "Semiconductor Nanowires for Energy Conversion," Chemical Reviews, Vol. 110, No. 1, 2010, pp. 527-546. http://dx.doi.org/10.1021/cr900075v 